\title{
PESQUISA COM CRIANÇAS SOBRE LEITURA E JOGOS DIGITAIS: INSTRUMENTOS METODOLÓGICOS NO PROCESSO DE CONSTRUÇÃO DE DADOS
}

\author{
RESEARCH WITH CHILDREN ABOUT READING AND \\ DIGITAL GAMES: METHODOLOGICAL INTRUMENTS IN \\ THE PROCESS OF BUILDING DATA
}

Adriana Ferreira Boeira ${ }^{1}$ Flávia Brocchetto Ramos ${ }^{2}$ Carla Beatris Valentini ${ }^{3}$

\section{RESUMO}

Este texto tem o objetivo de abordar instrumentos metodológicos explorados no processo de construção de dados em pesquisa empírica, de caráter qualitativo, que investigou estratégias de leitura aplicadas por crianças. Os interlocutores usam o site Click Jogos e são estudantes do $5^{\mathbf{o}}$ ano do Ensino Fundamental, em escola particular situada no município de Vacaria-RS. Esse site foi selecionado a partir da aplicação do questionário online, levando em consideração o interesse dos participantes. Assim, apoiando-se na Análise de Conteúdo de Bardin (1979, 2004), o corpus foi constituído pelos enunciados analisados a partir de duas fontes: um questionário online e protocolos verbais (ERICSSON; SIMON, 1993) de áudio e vídeo. Individualmente, os participantes relataram as ações executadas, enquanto liam e interagiam com jogos do seu interesse, disponíveis no site definido para a investigação. Os dados foram organizados, codificados e categorizados, a fim de produzir inferências sobre os percursos realizados pelos sujeitos durante o jogo e a leitura na tela. Os resultados indicam a importância dos protocolos verbais como instrumento para construção de dados de investigação, pois possibilitam a construção de corpus, composto de enunciados verbais, visuais (estáticos ou em movimento), sonoros e híbridos.

Palavras-chave: Crianças. Instrumentos Metodológicos. Jogos Digitais. Leitura.

\section{ABSTRACT}

The purpose of this text is to discuss methodological instruments explored in the process of building data in a qualitative empirical research which investigated reading strategies applied by children. The interlocutors use the website Click Jogos and they are $5^{\text {th }}$ grade students

\footnotetext{
${ }^{1}$ Professora do Ensino Básico, Técnico e Tecnológico do Instituto Federal de Educação, Ciência e Tecnologia do Rio Grande do Sul (IFRS), Campus Vacaria. Atualmente afastada para realização de pós-doutorado. O presente trabalho foi realizado com apoio do Instituto Federal de Educação, Ciência e Tecnologia do Rio Grande do Sul (IFRS). E-mail: adriana.boeira@vacaria.ifrs.edu.br, Orcid: https://orcid.org/0000-0002-1551-9222.

2 Professora do Programa de Pós-Graduação em Educação (PPGEdu/UCS) e do Programa de PósGraduação em Letras, Cultura e Regionalidade (PPGLet/ Associação Ampla UCS/UniRitter). Email: ramos.fb@gmail.com, Orcid: https://orcid.org/0000-0002-1488-0534.

${ }^{3}$ Professora e Coordenadora do Programa de Pós-Graduação em Educação (PPGEdu/UCS). Email: cbvalent@ucs.br, Orcid: https://orcid.org/0000-0003-0355-7712.
} 
at a private Elementary School in Vacaria - RS (Brazil). This website was chosen considering the interests of the participants from their answers to an online survey. Therefore, based on Bardin $(1979,2004)$ and Content Analysis, the corpus was built from utterances analyzed from two sources: an online survey and audio and video verbal protocols (ERICSSON; SIMON, 1993). Participants reported individually the actions executed by them while reading and interacting with games of their interest and available on the website defined for the investigation. Data were organized, codified and categorized in order to produce inferences on the path followed by the subjects during the game and reading on the screen. The results indicate how important verbal protocols can be as instruments to build research data since they enable the construction of the corpus, which is comprised of verbal, visual (static or in movement), sonorous and hybrid utterances.

Keywords: Children. Methodological Instruments. Digital Games. Reading.

\section{INTRODUÇÃO}

Os enunciados de leitura não se limitam a palavras registradas no papel, especialmente quando o seu suporte são diferentes telas, desktops, notebooks, tablets e smartphones, e se tem como objeto de leitura o jogo digital, constituído de hipertextos (LÉVY, 1996), compostos de enunciados verbais, visuais (imagens estáticas ou em movimento), sonoros e híbridos, combinando esses diferentes enunciados, tais como os vídeos, e se interligam. Considerando a importância de se explorar as possibilidades de leitura por meio de diferentes suportes, sobretudo a tela, foi realizado uma pesquisa empírica, de caráter qualitativo, com o objetivo de investigar o perfil de leitura dos estudantes do $5^{\circ}$ ano do Ensino Fundamental (EF) de uma escola particular situada no município de Vacaria-RS. O estudo analisou as estratégias de leitura empregadas por eles ao jogar, por meio da tela do notebook, a fim de contribuir para as discussões acerca do processo de leitura. Este artigo é recorte dessa pesquisa e tem o objetivo de abordar a metodologia, expondo os instrumentos metodológicos empregados no processo de construção de dados para análise.

Ressaltamos que a metodologia utilizada em investigações é um exercício autoral, é construída pelos pesquisadores, articulando procedimentos existentes e novos, configurando encaminhamento coerente com o objeto de estudo e com a fundamentação teórica da pesquisa. Para isso, no referido estudo, na construção dos dados foram exploradas: a criação e a aplicação de questionário online para verificar e selecionar o site do interesse dos participantes; e a produção dos protocolos verbais (ERICSSON; SIMON, 1993) de áudio e vídeo gerados por estudantes, enquanto liam e interagiam com jogos de sua preferência no site selecionado anteriormente. Após a obtenção dos dados, realizou-se a organização, codificação e categorização para a discussão, empregando a Análise de Conteúdo - AC - (BARDIN, 1979, 2004).

Assim, este artigo, primeiro, apresenta o processo da AC, que inicia pela obtenção do corpus até a produção da inferência pelo sujeito pesquisador. Em seguida, expõe os 
instrumentos metodológicos e procedimentos empregados na constituição do corpus, ou seja, como ocorreu a preparação, construção e seleção de documentos a serem submetidos à análise, utilizados na pesquisa como material empírico.

\section{Análise de Conteúdo: da obtenção do corpus à produção da inferência}

A Análise de Conteúdo (BARDIN, 1979, 2004), AC, "aparece como um conjunto de técnicas de análise das comunicações, que utiliza procedimentos sistemáticos e objectivos de descrição do conteúdo das mensagens" (BARDIN, 1979, p. 38) e tem como objetivo "a manipulação de mensagens (conteúdo e expressão desse conteúdo), para evidenciar os indicadores que permitam inferir sobre uma outra realidade que não a da mensagem" (BARDIN, 1979, p. 46). Portanto, a finalidade do pesquisador, analista, vai além de “compreender o sentido da comunicação (como se fosse um receptor normal), mas também e principalmente desviar o olhar para uma outra significação, uma outra mensagem entrevista através ou ao lado da mensagem primeira" (BARDIN, 1979, p. 41). Para isso, essa metodologia do domínio da análise textual, escritas e decifradas, exige do pesquisador a realização dos processos de organização, codificação e categorização do corpus, definido como "o conjunto de documentos tidos em conta para serem submetidos aos procedimentos analíticos" (BARDIN, 2004, p. 90).

As fases de organização, codificação e categorização são realizadas somente após ter posse do corpus, sendo organizado, explorado, tratado, descrito e interpretado pelo sujeito pesquisador ao produzir sentidos ao(s) objeto(s) e fenômeno(s) investigados quando elabora a inferência. Portanto, para alcançar a inferência é fundamental a dedicação aos processos de organização, codificação e categorização do corpus. Na fase de organização, o pesquisador realiza " a escolha dos documentos a serem submetidos à análise, a formulação das hipóteses e dos objectivos e a elaboração de indicadores que fundamentem a interpretação final" (BARDIN, 1979, p. 95). Depois da organização, ocorre o tratamento do material pela codificação:

[...] corresponde a uma transformação - efetuada segundo normas precisas - dos dados em bruto do texto, transformação esta que, por recorte, agregação e enumeração, permite atingir uma representação do conteúdo, ou da sua expressão susceptível de esclarecer o analista acerca das características do texto, que podem servir de índices (BARDIN, 2004, p. 97).

Assim, a operação de codificação do corpus exige o recorte, a escolha das unidades; a enumeração, a seleção das regras de contagem; e a classificação e agregação, a eleição das categorias (BARDIN, 1979, 2004); enquanto a operação de categorização consiste na 
[...] classificação de elementos constitutivos de um conjunto, por diferenciação e, seguidamente, por reagrupamento segundo o gênero (analogia), com critérios previamente definidos. As categorias são rubricas ou classes, que reúnem um grupo de elementos (unidades de registro, no caso da análise de conteúdo) sob um título genérico, agrupamento esse efetuado em razão dos caracteres comuns destes elementos (BARDIN, 2004, p. 97).

Contudo, antes de realizar essas fases da AC, é igualmente importante o pesquisador definir os instrumentos, procedimentos e recursos metodológicos adequados para a obtenção do corpus, podendo explorar materiais existentes: textos e imagens publicados em formato impresso ou digital; áudios; e vídeos, que combinam textos, sons, imagens estáticas e em movimento. Além dos materiais existentes, é possível produzir materiais para a construção do corpus, utilizando como instrumentos: questionários, entrevistas e protocolos verbais (ERICSSON; SIMON, 1993) de áudio e vídeo.

Dessa forma, conforme Figura 1, a pesquisa definiu como instrumentos para a obtenção do corpus a ser posteriormente organizado, codificado e categorizado: a) aplicação no laboratório de informática de questionário online criado pelo Google Forms, para verificar e selecionar o site do interesse dos participantes; b) produção de protocolos verbais (ERICSSON; SIMON, 1993) de áudio e vídeo pelo Camtasia Studio, no laboratório de informática, quando os participantes, utilizando o notebook da pesquisadora, relataram ações, procedimentos executados, enquanto liam e jogavam no site selecionado.

Figura 1: Instrumentos metodológicos

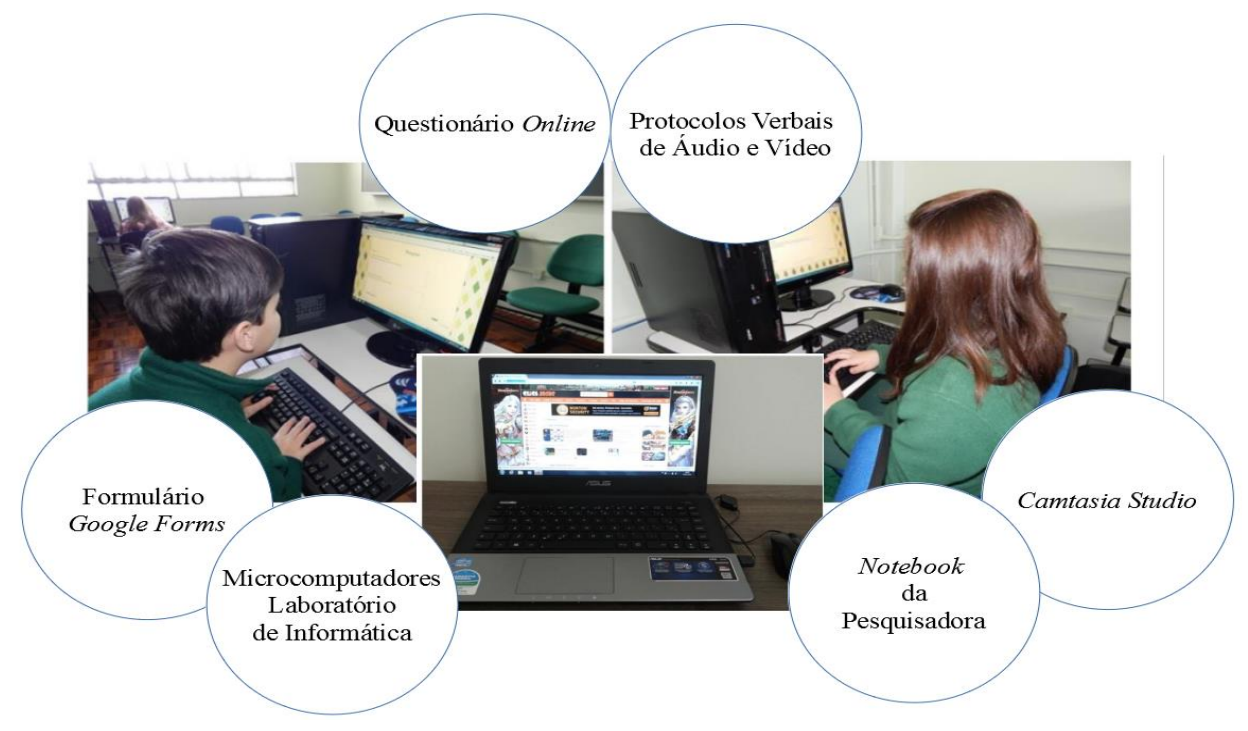

Fonte: Elaboração das autoras.

Essas ações, apresentadas nas próximas seções, foram realizadas após a assinatura do termo de autorização institucional e do Termo de Consentimento Livre e Esclarecido (TCLE) pela gestora e pelos responsáveis pelos sujeitos, respectivamente. 


\section{O questionário online}

Com o objetivo de identificar os interesses dos estudantes e quais os principais sites acessados por eles, a fim de selecionar um desses sites, em data previamente indicada, 20 estudantes, dos 23 que entregaram o TCLE preenchido e assinado, responderam ao questionário online ${ }^{l}$ no laboratório de informática da escola. O questionário online foi produzido pelas pesquisadoras, de forma gratuita, pelo Google Forms e composto por 58 questões, em 43 páginas. Apesar desta quantidade de páginas e de questões, cada página era composta por, no máximo, duas questões, e a maioria das questões, 40, eram de múltipla escolha. Além disso, as outras 18 questões exigiam a digitação de respostas curtas pelos estudantes. Depois do preenchimento do formulário, as informações foram enviadas automaticamente para uma planilha com acesso restrito, facilitando o armazenamento, a tabulação e garantindo a privacidade das informações fornecidas pelos sujeitos.

O laboratório de informática foi organizado, antecipadamente, para a realização da atividade: desktops ligados na página do questionário online. Após a chegada dos estudantes, nove meninas e 11 meninos, com faixa etária entre nove a 11 anos de idade; uma estudante com nove anos; 16 estudantes com dez anos (nove meninos e sete meninas) e três estudantes com 11 (dois meninos e uma menina), definimos os lugares ocupados pelos mesmos; esclarecemos, por meio da leitura das orientações escritas no quadro: durante a aplicação do questionário, eles deveriam respondê-lo sem pressa, individualmente, não consultar seus colegas, digitando as palavras corretamente.

Explicamos os diferentes tipos de itens do questionário: alguns, edit, deveriam digitar as suas respostas; outras, checkbox, com opções de respostas para serem assinaladas, mais de uma alternativa ou uma única opção. Também, esclarecemos a presença das questões obrigatórias, e a opção "Outra(s)/Outro(s)", permitindo digitar a resposta apropriada para a questão, caso esta não estivesse disponível na lista de opções.

Os estudantes foram orientados a ler as perguntas com bastante atenção; após responderem cada questão, para seguir, deveriam clicar no botão "Continuar", sendo impossível avançar sem o preenchimento das respostas das questões exibidas na tela. Portanto, não visualizavam quais seriam os itens posteriores. Quando terminassem todo o instrumento, apareceria uma mensagem, informando o registro da resposta e agradecendo a sua participação. 
Ressaltamos que, no início, não se buscava investigar a leitura realizada por estudantes, especificamente, por meio dos jogos digitais online, mas a leitura desses sujeitos, de forma geral, em sites infantis. A especificação ocorreu em virtude do interesse dos participantes, pois após a aplicação do questionário, constatamos: os sites destinados aos jogos são os eleitos por esse público, citando 12 diferentes sites de jogos, e não os de histórias ou livros para leitura.

Dessa forma, selecionamos e caracterizamos, para a produção dos protocolos verbais, o Click Jogos, porque foi o mais mencionado, por cinco sujeitos (três meninos e duas meninas), o qual é composto por grande quantidade de jogos digitais online, divididos em diversas categorias. O site apresenta aos usuários a descrição e a indicação da faixa etária de cada jogo; não exige cadastro e tem conteúdo apropriado e de interesse dos interlocutores. Assim, nesta pesquisa empírica, após a seleção e definição do site, os estudantes produziram protocolos verbais (ERICSSON; SIMON, 1993) de áudio e vídeo, enquanto liam e jogavam no Click Jogos, conforme apresenta a próxima seção.

\section{O protocolo verbal}

Ericsson e Simon (1993) defendem que o registro verbal dos sujeitos, o comportamento verbal, também pode ser gravado, observado e analisado, compondo o corpus de pesquisa de diversas áreas. Os autores ressaltam que, inicialmente, os psicólogos expuseram dúvidas sobre a adequação das verbalizações dos sujeitos como dados científicos e, diante disso, construíram uma teoria da verbalização, especificando quando, onde, e em que tipos de instruções os relatos verbais podem ser obtidos a partir dos sujeitos.

Há duas formas de relatos verbais, buscando ser o registro mais próximo dos processos cognitivos dos sujeitos (ERICSSON; SIMON, 1993). Uma das formas são os protocolos verbais "talk aloud" e "think aloud", "falar em voz alta" e "pensar em voz alta", nos quais os processos cognitivos são verbalizados, na realização da atividade pelo sujeito. A outra forma é por meio do protocolo verbal "retrospective", retrospectivo, realizado logo após ter sido finalizada a atividade pelo sujeito, exigindo o acesso às informações e a verbalização a partir da memória de curto prazo (STM, Short-Term Memory), pelo menos em parte, ou recuperando a memória de longo prazo (LTM, Long-Term Memory). Van Someren, Barnard e Sandberg (1994) advertêm: o protocolo verbal, quando exige a retrospecção, pode ser mais difícil para garantir a fidelidade do processo realizado pelo sujeito, sendo difícil para o participante lembrar exatamente de suas ações, especialmente, se passou algum tempo após a conclusão da tarefa. 
Por tentar produzir protocolos verbais mais completos com os estudantes, decidimos utilizar na pesquisa o protocolo verbal "talk aloud" e "think aloud", "falar em voz alta" e "pensar em voz alta", quando os participantes verbalizavam o que estavam fazendo e pensando no momento da realização das atividades propostas. Portanto, no laboratório de informática, em 15 encontros, no período de agosto a novembro, individualmente, os sujeitos produziram 18 protocolos verbais de áudio e vídeo: relataram na sequência as ações, os procedimentos executados e utilizados nos seus percursos, enquanto liam e jogavam no Click Jogos, inclusive dificuldades, interferências e qualquer outra informação pertinente.

Para Ericsson e Simon (1993), os avanços tecnológicos têm melhorado a nossa capacidade de tratar os protocolos verbais como dados de pesquisa. Assim, estão sendo utilizados diferentes recursos para a construção e para o armazenamento dos protocolos verbais. Entre eles, gravadores para capturar o áudio e filmadoras para capturar o áudio e a imagem/vídeo dos sujeitos. Nesta fase da pesquisa, utilizamos a câmera digital compacta ${ }^{2}$, como filmadora, e o notebook ${ }^{3}$. Apesar de o acesso ao site pelo notebook poder ser realizado somente com o deslizar e toque dos dedos, por meio do touchpad, fornecemos o mouse; assim, estudantes poderiam optar ou não pela utilização deste enquanto liam e jogavam no site.

No notebook, instalamos o software proprietário para captura das telas, Camtasia Studio, versão 8.2, escolhido não por permitir a criação e edição de vídeos, mas porque possibilitava, simultaneamente, capturar e armazenar o áudio, a imagem, vídeo e, sobretudo, capturar as telas, a trajetória, os movimentos do mouse, dos estudantes, enquanto liam e jogavam no site. Portanto, um único programa fornecia condições para compor o corpus, sendo os vídeos capturados pela câmera digital compacta explorados somente quando necessário analisar os arquivos além dos capturados pelo notebook.

Ainda, não seria necessário solicitar autorização para instalação desse programa nos desktops do laboratório de informática. Além disso, o notebook, por ser portátil, facilitava o seu transporte e instalação, e os interlocutores empíricos, em geral, também estão acostumados a utilizar os seus recursos. Os arquivos de áudio e vídeo obtidos, protocolos verbais, posteriormente, foram transcritos, compondo também o corpus da pesquisa. Assim, adotamos alguns procedimentos antes, durante e depois da produção do protocolo verbal, como será exposto a seguir.

\footnotetext{
2 Câmera digital compacta da escola, Nikon, modelo Coolpix L820, que possibilitava a captura e o armazenamento de vídeos.

${ }^{3}$ Notebook da pesquisadora, Asus A45A, com processador Intel ${ }^{\circledR}$ Core ${ }^{\mathrm{TM}}$ i5-3210M Dual Core, cache 3 MB e sistema operacional Windows® 7, tela de 14" tipo LCD LED resolução de 1366 x 768, gravador de DVD/CD, leitor de cartão SD, webcam integrada resolução 0.3 MP e wireless (Wi-Fi).
} 


\section{Antes do protocolo verbal}

Primeiramente, organizamos um cronograma incluindo a participação dos 20 estudantes $^{4}$ do $5^{\circ}$ ano do EF, de forma individual, da atividade de leitura, por meio dos jogos digitais online do Click Jogos. Enviamos bilhete, colado na agenda dos participantes, aos pais ou responsável, informando a data e horário dessa etapa da pesquisa ${ }^{5}$. O bilhete foi enviado não só para os 20 estudantes, mas também para os outros três, Gude, Velha e Resta Um, pois, apesar de não terem respondido ao questionário, não sendo possível recolher suas informações, haviam devolvido o TCLE com o objetivo de utilizar os protocolos verbais produzidos por eles como pilotos, a fim de testar e definir o tempo da atividade, o posicionamento da mesa, cadeira, notebook, câmera filmadora. Esses estudantes receberam os primeiros bilhetes, agendando a atividade de leitura por meio dos jogos digitais online no site no laboratório de informática. Resta Um não compareceu a nenhum dos agendamentos ${ }^{6}$. Dessa forma, foram utilizados como piloto os protocolos verbais produzidos por Gude e Velha.

O tempo máximo de 50 minutos, por cada participante, destinou-se à realização da atividade de leitura por meio dos jogos digitais online no site selecionado; nesse período, está inserido o tempo necessário para testar os equipamentos (notebook e programa instalado, a câmera e o microfone); também o tempo utilizado para explicar e demonstrar a atividade aos estudantes. Os protocolos verbais foram produzidos em 15 encontros, entre agosto a novembro, distribuídos nas seguintes datas: quatro dias do mês de agosto (15, 18, 22 e 29/08); cinco dias do mês de setembro (cinco, 12, 16, 19 e 26/09); dois dias do mês de outubro (nove e 31/10) e três dias do mês de novembro (sete, 14 e 21/11), conforme Quadro 1.

Quadro 1 - Cronograma da atividade de leitura por meio dos jogos digitais online no Click Jogos (continua)

\begin{tabular}{|c|c|c|c|c|c|c|c|c|c|}
\hline \multirow[t]{2}{*}{ Quant. } & \multirow[t]{2}{*}{ IDENT. } & \multirow{2}{*}{$\begin{array}{l}\text { DATA DO } \\
\text { ENVIO } \\
\text { BILHETE }\end{array}$} & DATA & HORÁRIO & \multirow{2}{*}{$\begin{array}{c}\text { OBS. } \\
\text { C } \\
\text { ou } \\
\text { NC } \\
{[3]}\end{array}$} & \multirow{2}{*}{$\begin{array}{l}\text { DATA DO } \\
\text { ENVIO 2. } \\
\text { BILHETE }\end{array}$} & DATA & $\begin{array}{c}\text { HORÁRI } \\
\text { O }\end{array}$ & \multirow{2}{*}{$\begin{array}{c}\mathrm{OBS} \\
\cdot \\
\mathrm{C} \text { ou } \\
\mathrm{NC}^{7}\end{array}$} \\
\hline & & & \multicolumn{2}{|c|}{$\begin{array}{c}\text { LEITURA - JOGO } \\
\text { SITE }\end{array}$} & & & \multicolumn{2}{|c|}{$\begin{array}{c}\text { LEITURA - JOGO } \\
\text { SITE }\end{array}$} & \\
\hline 1 & Gude & 07/08 & 08/08 & 9h10 às & $\mathrm{NC}$ & $14 / 08$ & $15 / 08$ & 9h10 às & $\mathrm{C}$ \\
\hline
\end{tabular}

\footnotetext{
${ }^{4}$ A partir de agora, de modo a evidenciar a presença e interesse pelos jogos, mesmo antes do surgimento dos digitais online, os estudantes são identificados por nomes de jogos, expostos em itálico.

5 As datas e horários eram agendados após consulta à profissional responsável pelo laboratório de informática, para evitar que as aulas marcadas pelos professores fossem canceladas ou transferidas. Da mesma forma, antes de colar o bilhete na agenda, conversava-se com os estudantes para verificar se era possível agendar a atividade em determinada data e horário; caso tivessem algum compromisso, era trocado o dia e horário para a realização da atividade pelo estudante por data e horário; ou era agendado com outro estudante realizando a atividade na data e horário previstos.

${ }^{6}$ Além de Resta Um, Quebra-cabeça, Stop, Gamão e Tangram não compareceram ao segundo agendamento para realizar a atividade de leitura do site.

${ }^{7} \mathrm{C}$ (compareceu) e NC (não compareceu).
} 


\begin{tabular}{|l|l|c|c|l|l|l|l|l|l|} 
& & & & $10 \mathrm{~h}$ & & & & $10 \mathrm{~h}$ & \\
\hline 2 & Velha & $14 / 08$ & $18 / 08$ & $\begin{array}{l}9 \mathrm{~h} 10 \text { às } \\
10 \mathrm{~h}\end{array}$ & $\mathrm{C}$ & & & & \\
\hline 3 & Resta um & $14 / 08$ & $15 / 08$ & $\begin{array}{l}10 \mathrm{~h} 20 \text { às } \\
11 \mathrm{~h} 10\end{array}$ & $\mathrm{NC}$ & $15 / 08$ & $18 / 08$ & $\begin{array}{l}10 \mathrm{~h} 10 \\
\text { às } 11 \mathrm{~h}\end{array}$ & $\mathrm{NC}$ \\
\hline 4 & $\begin{array}{l}\text { Sete } \\
\text { Erros }\end{array}$ & $21 / 08$ & $22 / 08$ & $\begin{array}{l}7 \mathrm{~h} 30 \text { às } \\
8 \mathrm{~h} 20\end{array}$ & $\mathrm{C}$ & & & & \\
\hline 5 & \begin{tabular}{l} 
Pontinho \\
\hline 6
\end{tabular} & $21 / 08$ & $22 / 08$ & $\begin{array}{l}10 \mathrm{~h} 10 \text { às } \\
11 \mathrm{~h}\end{array}$ & $\mathrm{C}$ & & & & \\
\hline 7 & $\begin{array}{l}\text { Amareli- } \\
\text { nha }\end{array}$ & $28 / 08$ & $29 / 08$ & $\begin{array}{l}9 \mathrm{~h} 10 \text { às } \\
10 \mathrm{~h}\end{array}$ & $\mathrm{NC}$ & $25 / 09$ & $26 / 09$ & $\begin{array}{l}9 \mathrm{~h} 10 \text { às } \\
10 \mathrm{~h}\end{array}$ & $\mathrm{C}$ \\
\hline 8 & $\begin{array}{l}\text { Dominó } \\
\text { Quebra- } \\
\text { cabeça }\end{array}$ & $04 / 09$ & $09 / 09$ & $\begin{array}{l}8 \mathrm{~h} 20 \text { às } \\
9 \mathrm{~h} 10\end{array}$ & $\mathrm{NC}$ & $27 / 11$ & $28 / 11$ & $\begin{array}{l}8 \mathrm{~h} 20 \text { às } \\
9 \mathrm{~h} 10\end{array}$ & $\mathrm{NC}$ \\
\hline
\end{tabular}

Quadro 1 - Cronograma da atividade de leitura por meio dos jogos digitais online no Click Jogos (conclusão)

\begin{tabular}{|c|c|c|c|c|c|c|c|c|c|}
\hline \multirow[t]{2}{*}{ Quant. } & \multirow[t]{2}{*}{ IDENT. } & \multirow{2}{*}{$\begin{array}{c}\text { DATA DO } \\
\text { ENVIO } \\
\text { BILHETE }\end{array}$} & DATA & HORÁRIO & \multirow{2}{*}{$\begin{array}{c}\text { OBS. } \\
\text { C } \\
\text { ou } \\
\text { NC } \\
{[3]}\end{array}$} & \multirow{2}{*}{$\begin{array}{l}\text { DATA DO } \\
\text { ENVIO 2. } \\
\text { BILHETE }\end{array}$} & DATA & $\begin{array}{c}\text { HORÁRI } \\
\text { O }\end{array}$ & \multirow{2}{*}{$\begin{array}{l}\mathrm{OBS} \\
\mathrm{Cou} \\
\mathrm{NC}\end{array}$} \\
\hline & & & \multicolumn{2}{|c|}{$\begin{array}{l}\text { LEITURA - JOGO } \\
\text { SITE }\end{array}$} & & & \multicolumn{2}{|c|}{$\begin{array}{c}\text { LEITURA - JOGO } \\
\text { SITE }\end{array}$} & \\
\hline 9 & Forca & $04 / 09$ & $05 / 09$ & $\begin{array}{l}9 \mathrm{~h} 10 \text { às } \\
10 \mathrm{~h}\end{array}$ & $\mathrm{C}$ & & & & \\
\hline 10 & Stop & 04/09 & 09/09 & $\begin{array}{l}8 \mathrm{~h} 20 \text { às } \\
9 \mathrm{~h} 10\end{array}$ & $\mathrm{NC}$ & $27 / 11$ & $28 / 11$ & $\begin{array}{l}9 \mathrm{~h} 10 \text { às } \\
10 \mathrm{~h}\end{array}$ & $\mathrm{NC}$ \\
\hline 11 & $\begin{array}{l}\text { Pega- } \\
\text { varetas }\end{array}$ & $11 / 09$ & $16 / 09$ & $\begin{array}{l}9 \mathrm{~h} 10 \text { às } \\
10 \mathrm{~h}\end{array}$ & $\mathrm{NC}$ & $18 / 09$ & $19 / 09$ & $\begin{array}{l}9 \mathrm{~h} 10 \text { às } \\
10 \mathrm{~h}\end{array}$ & $\mathrm{C}$ \\
\hline 12 & $\begin{array}{l}\text { Cinco } \\
\text { Marias }\end{array}$ & $11 / 09$ & $12 / 09$ & $\begin{array}{l}9 \mathrm{~h} 10 \text { às } \\
10 \mathrm{~h}\end{array}$ & $\mathrm{C}$ & & & & \\
\hline 13 & Buraco & $11 / 09$ & $16 / 09$ & $\begin{array}{l}10 \mathrm{~h} 10 \text { às } \\
11 \mathrm{~h}\end{array}$ & $\mathrm{C}$ & & & & \\
\hline 14 & Gamão & $18 / 09$ & $19 / 09$ & $\begin{array}{l}10 \mathrm{~h} 10 \text { às } \\
11 \mathrm{~h}\end{array}$ & $\mathrm{NC}$ & $25 / 09$ & $26 / 09$ & $\begin{array}{l}8 \mathrm{~h} 20 \text { às } \\
9 \mathrm{~h} 10\end{array}$ & $\mathrm{NC}$ \\
\hline 15 & $\begin{array}{l}\text { Dormi- } \\
\text { nhoco }\end{array}$ & $08 / 10$ & $09 / 10$ & $\begin{array}{l}10 \mathrm{~h} 10 \text { às } \\
11 \mathrm{~h}\end{array}$ & $\mathrm{C}$ & & & & \\
\hline 16 & Memória & $08 / 10$ & $09 / 10$ & $\begin{array}{l}9 \mathrm{~h} 10 \text { às } \\
10 \mathrm{~h}\end{array}$ & $\mathrm{C}$ & & & & \\
\hline 17 & Tangram & $09 / 10$ & $10 / 10$ & $\begin{array}{l}9 \mathrm{~h} 10 \text { às } \\
10 \mathrm{~h}\end{array}$ & $\mathrm{NC}$ & $27 / 11$ & $28 / 11$ & $\begin{array}{l}11 \mathrm{~h} 10 \\
\text { às } 12 \mathrm{~h}\end{array}$ & $\mathrm{NC}$ \\
\hline 18 & $\begin{array}{l}\text { Caça- } \\
\text { Palavras }\end{array}$ & $16 / 10$ & $17 / 10$ & $\begin{array}{l}9 \mathrm{~h} 10 \text { às } \\
10 \mathrm{~h}\end{array}$ & $\mathrm{NC}$ & $30 / 10$ & $31 / 10$ & $\begin{array}{l}9 \mathrm{~h} 10 \text { às } \\
10 \mathrm{~h}\end{array}$ & $\mathrm{C}$ \\
\hline
\end{tabular}

\footnotetext{
${ }^{8} \mathrm{C}$ (compareceu) e NC (não compareceu).
} 

Dados

\begin{tabular}{|l|l|c|c|l|l|l|l|l|l|}
\hline 19 & Damas & $06 / 11$ & $07 / 11$ & $\begin{array}{l}9 \mathrm{~h} 10 \text { às } \\
10 \mathrm{~h}\end{array}$ & $\mathrm{C}$ & & & & \\
\hline 20 & Xadrez & $06 / 11$ & $07 / 11$ & $\begin{array}{l}10 \mathrm{~h} 20 \text { às } \\
11 \mathrm{~h} 10\end{array}$ & $\mathrm{C}$ & & & & \\
\hline 21 & Caçador & $13 / 11$ & $14 / 11$ & $\begin{array}{l}9 \mathrm{~h} 10 \text { às } \\
10 \mathrm{~h}\end{array}$ & $\mathrm{C}$ & & & & \\
\hline 22 & $\begin{array}{l}\text { Palavra- } \\
\text { cruzada }\end{array}$ & $13 / 11$ & $14 / 11$ & $\begin{array}{l}10 \mathrm{~h} 10 \text { às } \\
11 \mathrm{~h}\end{array}$ & $\mathrm{C}$ & & & & \\
\hline 23 & Trilha & $20 / 11$ & $21 / 11$ & $\begin{array}{l}9 \mathrm{~h} 10 \text { às } \\
10 \mathrm{~h}\end{array}$ & $\mathrm{C}$ & & & & \\
\hline
\end{tabular}

Fonte: Pesquisa "Ler e jogar ou jogar e ler? Estratégias de leitura empregadas por estudantes do $5^{\circ}$ ano do Ensino Fundamental ao jogar no Click Jogos".

O bilhete foi enviado aos pais ou responsável, colado na agenda dos estudantes no dia anterior ao da realização da leitura ou próximo, no máximo cinco dias, do dia da realização da atividade. Além disso, procuramos agendar somente dois estudantes por dia, em horários diferenciados, conciliando essa ação com suas atividades profissionais ${ }^{9}$.

Apesar de tentar marcar as datas e horários, após consultar os estudantes, em dia e horário possíveis de eles participarem, nove deles (cinco meninos e quatro meninas) não compareceram na data e horário marcado para a realização da atividade. Assim, agendamos segunda data com os nove estudantes; destes, quatro estudantes (meninas) compareceram, na data e horário marcado; cinco (meninos), novamente, não compareceram ao segundo agendamento. Alguns deles justificaram a ausência na atividade, entre os motivos, pelo mau tempo e, principalmente, compromissos, imprevistos, atrasos ou esquecimentos dos pais ou responsável, impossibilitando-os de levarem os estudantes à escola para participar da ação.

A cada dia marcado com os participantes para a atividade de leitura por meio dos jogos digitais online no site, antecipadamente, preparava-se o laboratório de informática: verificava se o ambiente estava organizado (desktops desligados, cadeiras nos lugares, quadro apagado); abria as janelas; posicionava a câmera filmadora, a mesa, a cadeira e o notebook a ser utilizado pelos sujeitos sempre na mesma disposição; ligava o notebook; testava o acesso ao site, o programa de captura da tela (o volume do microfone e a posição da webcam) e a câmera filmadora, para gravar os movimentos corporais dos estudantes durante a realização da atividade.

\footnotetext{
${ }^{9}$ Embora tenha sido realizado um planejamento para conciliar as atividades profissionais com atividade de pesquisa realizada no laboratório de informática da instituição, tentando não prejudicar nenhuma das atividades (as profissionais e a pesquisa), nem sempre isso foi possível, pois alguns imprevistos aconteceram, interrompendo a atividade de pesquisa por alguns minutos ou as acelerando a fim de resolver as situações ocorridas: presença de pais sem agendamento, conversa com os estudantes do EF ou EM, entre outras.
} 
Antes de iniciar a atividade de leitura por meio dos jogos digitais online no Click Jogos, posicionava-se cada estudante em frente ao notebook; testava volume do microfone; iniciava a filmagem por meio da câmera; iniciava o programa Camtasia Studio e explicava as atividades a serem realizadas pelo participante: primeiro, deveria acessar o site selecionado, o Click Jogos, <http://clickjogos.uol.com.br/>; e depois um site escolhido pelo estudante; o seu preferido, sem contar o Facebook, Instagram, YouTube, o site da escola ou qualquer outro site com conteúdo inadequado.

Explicamos, detalhadamente, como cada estudante participaria: deveria falar, com voz pausada e alta, o que estava fazendo e pensando enquanto realizasse as suas ações nos sites, a partir dos questionamentos. Além de explicar, fizemos demonstração: enquanto realizamos as ações, relatamos como se pensássemos alto: clicamos no navegador para acessar a Internet; acessamos e navegamos no site da escola; lemos algumas notícias e visualizamos fotos; saímos da Internet. Finalmente, esclarecemos as dúvidas dos estudantes com relação à execução da atividade, antes de iniciar a produção dos seus protocolos verbais.

\section{Durante o protocolo verbal}

Posicionado à frente do notebook, após todos os testes de funcionamento dos programas e equipamentos para a captura de áudio e vídeo; também depois as explicações e demonstrações e esclarecimentos de dúvidas do participante, iniciava-se a produção do protocolo verbal, a partir da atividade de leitura, por meio dos jogos digitais online no Click Jogos pelo estudante.

Para isso, os participantes deveriam agir e verbalizar suas ações a partir das perguntas, do formulário impresso, no qual preenchemos a data, o horário e o nome do estudante, além de observações feitas durante a realização da atividade. Inicialmente, questionamos como o estudante acessava o Click Jogos. Após a demonstração e verbalização do sujeito, interrogamos o participante: como elegia um jogo digital online, o que lia e por quê. Após, examinamos como ele jogava, ou seja, enquanto jogava, para atingir os objetivos propostos pelo jogo, o estudante verbalizava suas ações. Depois de finalizar o jogo digital online, ou quando o sujeito demostrava não estar mais interessado pelo mesmo, interrogamos como ele escolhia outro jogo no referido site, repetindo os questionamentos anteriores. Finalmente, o interlocutor verbalizava como ele saía do site.

Encerrada a navegação no Click Jogos, a partir dos mesmos questionamentos, os estudantes deveriam acessar outro site, de sua preferência, sem contar o site da escola, Facebook, Instagram, YouTube, ou qualquer outro com conteúdos inadequados, eleger e jogar 
um jogo digital, verbalizando suas ações. Assim, os sujeitos demonstraram como acessavam, o que liam, como optavam, jogavam e saiam do site ${ }^{10}$. Não transcrevemos a atividade de leitura no site escolhido pelo participante, embora realizada e autorizada pelos pais ou responsável no TCLE, em virtude da grande diversidade de sites nomeados pelas crianças e, principalmente, da quantidade de enunciados produzidos nos protocolos verbais, enquanto leram e jogaram no Click Jogos, suficientes para a análise.

Mesmo sendo testada antecipadamente, a câmera não filmou a totalidade da atividade realizada por Amarelinha e Dorminhoco; a resolução de vídeo configurada para a gravação era muito alta e não havia espaço na memória da câmera, por não possuir cartão de memória adicional. Ainda, a filmagem da atividade de Memória, por meio da câmera, ficou sem foco. Porém, embora não tenha sido possível filmar os movimentos corporais por meio da câmera, foram registradas as expressões faciais desses estudantes por meio do programa Camtasia Studio, instalado no notebook. Além do problema detectado na filmagem dos movimentos corporais, o notebook não registrou o percurso realizado por Dorminhoco no site, desligando-se duas vezes durante a atividade.

Assim, a partir da utilização de dois protocolos dos interlocutores como testes; o não comparecimento de cinco estudantes nos agendamentos; os três problemas detectados (duas interrupções e falha) na filmadora; e o problema de desligamento do notebook durante a realização da atividade, reduz-se as possibilidades de utilização dos 23 protocolos verbais possíveis, a partir do aceite em participar da pesquisa por meio do TCLE, dos estudantes do $5^{\circ}$ ano do EF. Portanto, fizemos o primeiro filtro para selecionar os protocolos verbais para posterior transcrição e constatamos a possibilidade de transcrever até 12 protocolos verbais produzidos a partir da leitura dos jogos digitais online do Click Jogos, conforme Quadro 2.

Quadro 2 - Protocolos possíveis de transcrição (continua)

\begin{tabular}{|c|c|c|c|c|c|c|c|c|c|}
\hline \multirow[t]{2}{*}{ Quant. } & \multirow[t]{2}{*}{ IDENT. } & \multirow[t]{2}{*}{$\begin{array}{l}\text { DATA DO } \\
\text { ENVIO } \\
\text { BILHETE }\end{array}$} & DATA & HORÁRIO & \multirow{2}{*}{$\begin{array}{c}\text { OBS. } \\
\text { C } \\
\text { ou } \\
\text { NC } \\
{[3]}\end{array}$} & \multirow[t]{2}{*}{$\begin{array}{l}\text { DATA DO } \\
\text { ENVIO 2. } \\
\text { BILHETE }\end{array}$} & DATA & $\begin{array}{c}\text { HORÁRI } \\
\text { O }\end{array}$ & \multirow{2}{*}{$\begin{array}{c}\mathrm{OBS} \\
\cdot \\
\mathrm{C} \text { ou } \\
\mathrm{NC}^{11}\end{array}$} \\
\hline & & & \multicolumn{2}{|c|}{$\begin{array}{c}\text { LEITURA - JOGO } \\
\text { SITE }\end{array}$} & & & \multicolumn{2}{|c|}{$\begin{array}{c}\text { LEITURA - JOGO } \\
\text { SITE }\end{array}$} & \\
\hline 1 & Pontinho & $21 / 08$ & $22 / 08$ & $\begin{array}{l}10 \mathrm{~h} 10 \text { às } \\
11 \mathrm{~h}\end{array}$ & $\mathrm{C}$ & & & & \\
\hline 2 & Dominó & $28 / 08$ & $29 / 08$ & $\begin{array}{l}10 \mathrm{~h} 10 \text { às } \\
11 \mathrm{~h}\end{array}$ & $\mathrm{C}$ & & & & \\
\hline
\end{tabular}

\footnotetext{
${ }^{10}$ Ao encerrar a atividade de leitura com cada estudante, agradecia-se a sua participação e os acompanhava até a recepção da escola, informando seus pais ou responsável de que a atividade havia sido encerrada e estes pudessem buscá-los. Dessa forma, enquanto os sujeitos esperam a chegada de seus pais na recepção, retornavase para o laboratório a fim de salvar, arquivar e organizar os arquivos produzidos enquanto os participantes leram e jogaram nos sites.

${ }^{11} \mathrm{C}$ (compareceu) e NC (não compareceu).
} 


\begin{tabular}{|l|l|c|c|l|l|l|l|l|l|}
3 & Forca & $04 / 09$ & $05 / 09$ & $\begin{array}{l}9 \mathrm{~h} 10 \text { às } \\
10 \mathrm{~h}\end{array}$ & $\mathrm{C}$ & & & & \\
\hline 4 & $\begin{array}{l}\text { Pega- } \\
\text { varetas }\end{array}$ & $11 / 09$ & $16 / 09$ & $\begin{array}{l}9 \mathrm{~h} 10 \text { às } \\
10 \mathrm{~h}\end{array}$ & NC & $18 / 09$ & $19 / 09$ & $\begin{array}{l}9 \mathrm{~h} 10 \text { às } \\
10 \mathrm{~h}\end{array}$ & \\
\hline 5 & $\begin{array}{l}\text { Cinco } \\
\text { Marias }\end{array}$ & $11 / 09$ & $12 / 09$ & $\begin{array}{l}9 \mathrm{~h} 10 \mathrm{às} \\
10 \mathrm{~h}\end{array}$ & $\mathrm{C}$ & & & & \\
\hline 6 & Buraco & $11 / 09$ & $16 / 09$ & $\begin{array}{l}10 \mathrm{~h} 10 \text { às } \\
11 \mathrm{~h}\end{array}$ & $\mathrm{C}$ & & & & \\
\hline
\end{tabular}

Quadro 2 - Protocolos possíveis de transcrição (conclusão)

\begin{tabular}{|c|c|c|c|c|c|c|c|c|c|}
\hline \multirow[t]{2}{*}{ Quant. } & \multirow[t]{2}{*}{ IDENT. } & \multirow[t]{2}{*}{$\begin{array}{l}\text { DATA DO } \\
\text { ENVIO } \\
\text { BILHETE }\end{array}$} & DATA & HORÁRIO & \multirow{2}{*}{$\begin{array}{c}\text { OBS. } \\
\text { C } \\
\text { ou } \\
\text { NC } \\
{[3]}\end{array}$} & \multirow[t]{2}{*}{$\begin{array}{l}\text { DATA DO } \\
\text { ENVIO 2. } \\
\text { BILHETE }\end{array}$} & DATA & $\begin{array}{c}\text { HORÁRI } \\
\text { O }\end{array}$ & \multirow{2}{*}{$\begin{array}{c}\mathrm{OBS} \\
\mathrm{C} \text { ou } \\
\mathrm{NC}^{12}\end{array}$} \\
\hline & & & \multicolumn{2}{|c|}{$\begin{array}{c}\text { LEITURA - JOGO } \\
\text { SITE }\end{array}$} & & & \multicolumn{2}{|c|}{$\begin{array}{c}\text { LEITURA - JOGO } \\
\text { SITE }\end{array}$} & \\
\hline 7 & $\begin{array}{l}\text { Caça- } \\
\text { Palavras }\end{array}$ & $16 / 10$ & $17 / 10$ & $\begin{array}{l}9 \mathrm{~h} 10 \text { às } \\
10 \mathrm{~h}\end{array}$ & $\mathrm{NC}$ & $30 / 10$ & $31 / 10$ & $\begin{array}{l}9 \mathrm{~h} 10 \text { às } \\
10 \mathrm{~h}\end{array}$ & \\
\hline 8 & Damas & $06 / 11$ & $07 / 11$ & $\begin{array}{l}9 \mathrm{~h} 10 \text { às } \\
10 \mathrm{~h}\end{array}$ & $\mathrm{C}$ & & & & \\
\hline 9 & Xadrez & $06 / 11$ & $07 / 11$ & $\begin{array}{l}10 \mathrm{~h} 20 \text { às } \\
11 \mathrm{~h} 10\end{array}$ & $\mathrm{C}$ & & & & \\
\hline 10 & Caçador & $13 / 11$ & $14 / 11$ & $\begin{array}{l}9 \mathrm{~h} 10 \text { às } \\
10 \mathrm{~h}\end{array}$ & $\mathrm{C}$ & & & & \\
\hline 11 & $\begin{array}{l}\text { Palavra- } \\
\text { cruzada }\end{array}$ & $13 / 11$ & $14 / 11$ & $\begin{array}{l}10 \mathrm{~h} 10 \text { às } \\
11 \mathrm{~h}\end{array}$ & $\mathrm{C}$ & & & & \\
\hline 12 & Trilha & $20 / 11$ & $21 / 11$ & $\begin{array}{l}9 \mathrm{~h} 10 \text { às } \\
10 \mathrm{~h}\end{array}$ & $\mathrm{C}$ & & & & \\
\hline
\end{tabular}

Fonte: Pesquisa "Ler e jogar ou jogar e ler? Estratégias de leitura empregadas por estudantes do $5^{\circ}$ ano do Ensino Fundamental ao jogar no Click Jogos".

Depois de reunirmos os 12 protocolos, cinco de meninos e sete de meninas, que poderiam ser utilizados na pesquisa, iniciamos o processo de organização, codificação e categorização do corpus, conforme se apresenta na próxima seção.

\section{Após o protocolo verbal}

A soma do tempo de gravação dos 12 protocolos verbais aptos à transcrição totalizou três horas e 39 minutos, média de 18,25 (Tabela 1). Porém, ressaltamos a diferença no tempo de acesso ao site entre os estudantes meninas e meninos; enquanto as sete meninas acessaram o site por 160 minutos, os cinco meninos acessaram por 59 minutos; média de 22,85 e 11,8 minutos, respectivamente. Os 12 estudantes do $5^{\circ}$ ano do EF escolheram 22 jogos diferentes;

\footnotetext{
${ }^{12} \mathrm{C}$ (compareceu) e NC (não compareceu).
} 
repetiu-se a opção do jogo "Soccer Physics" por dois (meninos) e do "Papa's CupCakeria" por duas (meninas).

Tabela 1 - Informações sobre os protocolos verbais ${ }^{13}$

\begin{tabular}{|c|c|c|c|c|c|c|c|}
\hline & $\begin{array}{c}\text { IDENT. } \\
\text { SITE } \\
\text { PROT. } \\
\text { VERBAL }\end{array}$ & DATA & $\begin{array}{c}\text { HORÁ } \\
\text { RIO }\end{array}$ & $\begin{array}{c}\text { HORÁRIO } \\
\text { DE } \\
\text { REALIZA- } \\
\text { ÇÃAO } \\
\end{array}$ & $\underset{\text { nu-tos }}{\text { Mi }}$ & JOGO 1 & JOGO 2 \\
\hline & & & $\begin{array}{c}\text { LEITURA } \\
\text { JOGO } \\
\text { SITE }\end{array}$ & & & & \\
\hline 1 & Pontinho & $22 / 08$ & $\begin{array}{l}10 \mathrm{~h} 10 \\
\text { às } 11 \mathrm{~h}\end{array}$ & $\begin{array}{c}\text { 10h17 às } \\
10 \mathrm{~h} 28\end{array}$ & 11 & Gibbets 4 & $\begin{array}{c}\text { Defend your } \\
\text { Nuts }\end{array}$ \\
\hline 2 & Dominó & $29 / 08$ & $\begin{array}{l}10 \mathrm{~h} 10 \\
\text { às } 11 \mathrm{~h}\end{array}$ & $\begin{array}{c}\text { 10h11 às } \\
10 \mathrm{~h} 22\end{array}$ & 11 & $\begin{array}{l}\text { Soccer } \\
\text { Physics }\end{array}$ & $\begin{array}{c}\text { Os } \\
\text { Simpsons - } \\
\text { The Ball Of } \\
\text { Death }\end{array}$ \\
\hline 3 & Forca & $05 / 09$ & $\begin{array}{l}9 \mathrm{~h} 10 \\
\text { às } 10 \mathrm{~h}\end{array}$ & $\begin{array}{l}9 \text { 9h26 às } \\
9 \text { h46 }\end{array}$ & 20 & $\begin{array}{l}\text { Operetta - } \\
\text { Monster }\end{array}$ & $\begin{array}{l}\text { Super Car } \\
\text { Wash }\end{array}$ \\
\hline 4 & $\begin{array}{l}\text { Cinco } \\
\text { Marias }\end{array}$ & $12 / 09$ & $\begin{array}{l}9 \mathrm{~h} 10 \\
\text { às } 10 \mathrm{~h}\end{array}$ & $\begin{array}{c}\text { 9h27 às } \\
9 \text { h36 }\end{array}$ & 9 & $\begin{array}{c}\text { Papa's } \\
\text { CupCakeria }\end{array}$ & $\begin{array}{l}\text { Bella's } \\
\text { Wedding } \\
\text { Cake }\end{array}$ \\
\hline 5 & Buraco & $16 / 09$ & $\begin{array}{l}10 \mathrm{~h} 10 \\
\text { às } 11 \mathrm{~h}\end{array}$ & $\begin{array}{c}10 h 36 \text { às } \\
10 h 51\end{array}$ & 15 & $\begin{array}{l}\text { Soccer } \\
\text { Physics }\end{array}$ & $\begin{array}{c}\text { Mestre dos } \\
\text { Droides }\end{array}$ \\
\hline 6 & $\begin{array}{l}\text { Pega- } \\
\text { varetas }\end{array}$ & $19 / 09$ & $\begin{array}{l}9 \mathrm{~h} 10 \\
\text { às } 10 \mathrm{~h}\end{array}$ & $\begin{array}{l}\text { 9h24 às } \\
\text { 9h49 }\end{array}$ & 25 & $\begin{array}{c}\text { Cicily's } \\
\text { Vegetable }\end{array}$ & $\begin{array}{c}\text { Papa's Hot } \\
\text { Doggeria }\end{array}$ \\
\hline 7 & $\begin{array}{l}\text { Caça- } \\
\text { Palavras }\end{array}$ & $31 / 10$ & $\begin{array}{c}9 \mathrm{~h} 10 \text { às } \\
10 \mathrm{~h}\end{array}$ & $\begin{array}{l}\text { 9h28 às } \\
9 \text { h45 }\end{array}$ & 17 & $\begin{array}{c}\text { Fairy } \\
\text { Princess }\end{array}$ & $\begin{array}{l}\text { Wedding } \\
\text { Banquet }\end{array}$ \\
\hline 8 & Damas & $07 / 11$ & $\begin{array}{c}9 \mathrm{~h} 10 \text { às } \\
10 \mathrm{~h}\end{array}$ & $\begin{array}{l}\text { 9h12 às } \\
9 h 30\end{array}$ & 18 & $\begin{array}{c}\text { Stan - Meu } \\
\text { Novo } \\
\text { Cãozinho }\end{array}$ & $\begin{array}{c}\text { Strawberry } \\
\text { Short Cake } 2\end{array}$ \\
\hline 9 & Xadrez & $07 / 11$ & $\begin{array}{l}10 \mathrm{~h} 20 \\
\text { às } \\
11 \mathrm{~h} 10\end{array}$ & $\begin{array}{c}\text { 10h29 às } \\
10 \mathrm{~h} 42\end{array}$ & 13 & $\begin{array}{l}\text { Birdy } \\
\text { Fruit }\end{array}$ & Billiards \\
\hline 10 & Caçador & $14 / 11$ & $\begin{array}{c}9 \mathrm{~h} 10 \text { às } \\
10 \mathrm{~h}\end{array}$ & $\begin{array}{c}9 \mathrm{~h} 20 \\
\text { às 9h29 }\end{array}$ & 9 & $\begin{array}{c}\text { Roby Baggio } \\
\text { Magical }\end{array}$ & Van Gaal \\
\hline 11 & $\begin{array}{l}\text { Palavra- } \\
\text { cruzada }\end{array}$ & $14 / 11$ & $\begin{array}{l}10 \mathrm{~h} 10 \\
\text { às } 11 \mathrm{~h}\end{array}$ & $\begin{array}{c}\text { 10h32 } \\
\text { às 11h11 }\end{array}$ & 39 & $\begin{array}{c}\text { Papa's } \\
\text { Wingeria }\end{array}$ & $\begin{array}{c}\text { Papa's Cup } \\
\text { Cakeria }\end{array}$ \\
\hline 12 & Trilha & $21 / 11$ & $\begin{array}{c}9 \mathrm{~h} 10 \text { às } \\
10 \mathrm{~h}\end{array}$ & $\begin{array}{c}9 \mathrm{~h} 21 \\
\text { às 9h53 }\end{array}$ & 32 & $\begin{array}{l}\text { Messy } \\
\text { Talking } \\
\text { Ginger }\end{array}$ & $\begin{array}{c}\text { Papa's Cup } \\
\text { Cakeria }\end{array}$ \\
\hline & & & & \multicolumn{2}{|c|}{ Total: 219 minutos } & & \\
\hline
\end{tabular}

${ }^{13}$ Os protocolos dos estudantes Pega-varetas e Caça-Palavras foram realizados a partir do segundo agendamento.

${ }^{14}$ Neste tempo não está inserido o tempo destinado às explicações, demonstração e esclarecimentos de dúvidas dos estudantes. 
Fonte: Pesquisa "Ler e jogar ou jogar e ler? Estratégias de leitura empregadas por estudantes do $5^{\circ}$ ano do Ensino Fundamental ao jogar no Click Jogos".

A partir da tabulação e análise geral dos protocolos dos 12 estudantes, consideramos os seguintes critérios para selecionar os quatro protocolos verbais a serem transcritos, compondo o corpus da pesquisa, os quais foram transcritos, organizados, codificados, categorizados e analisados: o envolvimento e os diferentes tipos de jogos escolhidos pelos sujeitos, que representassem a modalidade dos jogos de interesse dos outros estudantes, isto é, também escolhidos por outros sujeitos; o gênero masculino e feminino e as idades distintas dos participantes; e as datas e os horários variadas de produção. Além disso, observamos: o tempo de leitura e jogo no Click Jogos (nem o maior, nem o menor, das meninas e dos meninos) e a clareza na exposição das ações pelos estudantes.

Em síntese, os quatro protocolos verbais selecionados representam: dois protocolos de meninas, Damas e Trilha, e dois de meninos, Xadrez e Dominó, sendo dois estudantes (uma menina e um menino) com 10 anos e dois (uma menina e um menino) com 11 anos de idade, totalizando uma hora e 14 minutos, média de 18,5 minutos (superior à média geral dos protocolos). Destes, 50 minutos correspondem ao acesso das meninas e 24 minutos, ao acesso dos meninos; média de 25 e 12 minutos, respectivamente; médias superiores às médias gerais de acesso, conforme Tabela 2.

Tabela 2 - Protocolos verbais selecionados

\begin{tabular}{|c|c|c|c|c|c|c|c|}
\hline & \multirow{2}{*}{$\begin{array}{c}\text { IDENT. } \\
\text { SITE } \\
\text { PROT. } \\
\text { VERBAL }\end{array}$} & DATA & HORÁRIO & \multirow{2}{*}{$\begin{array}{l}\text { HORÁRIO } \\
\text { DE } \\
\text { REALIZA- } \\
\text { ÇÃO }\end{array}$} & \multirow{2}{*}{$\begin{array}{l}\text { Mi } \\
\text { nu- } \\
\text { tos }\end{array}$} & \multirow[t]{2}{*}{ JOGO 1} & \multirow[t]{2}{*}{ JOGO 2} \\
\hline & & \multicolumn{2}{|c|}{$\begin{array}{l}\text { LEITURA JOGO } \\
\text { SITE }\end{array}$} & & & & \\
\hline 1 & Dominó & $29 / 08$ & $\begin{array}{l}10 \mathrm{~h} 10 \\
\text { às } 11 \mathrm{~h}\end{array}$ & $\begin{array}{l}\text { 10h11 às } \\
10 \mathrm{~h} 22\end{array}$ & 11 & Soccer Physics & $\begin{array}{c}\text { Os Simpsons - } \\
\text { The Ball Of } \\
\text { Death }\end{array}$ \\
\hline 2 & Damas & $07 / 11$ & $9 \mathrm{~h} 10$ às $10 \mathrm{~h}$ & $\begin{array}{l}9 \text { h12 às } \\
9 \text { h30 }\end{array}$ & 18 & $\begin{array}{c}\text { Stan - Meu Novo } \\
\text { Cãozinho }\end{array}$ & $\begin{array}{c}\text { Strawberry Short } \\
\text { Cake } 2\end{array}$ \\
\hline 3 & Xadrez & $07 / 11$ & $\begin{array}{l}\text { 10h20 às } \\
11 \mathrm{~h} 10\end{array}$ & $\begin{array}{l}\text { 10h29 às } \\
10 \mathrm{~h} 42\end{array}$ & 13 & $\begin{array}{l}\text { Birdy } \\
\text { Fruit }\end{array}$ & Billiards \\
\hline 4 & Trilha & $21 / 11$ & $9 \mathrm{~h} 10$ às $10 \mathrm{~h}$ & $\begin{array}{c}\text { 9h21 } \\
\text { às 9h53 }\end{array}$ & 32 & $\begin{array}{l}\text { Messy Talking } \\
\text { Ginger }\end{array}$ & $\begin{array}{c}\text { Papa's Cup } \\
\text { Cakeria }\end{array}$ \\
\hline & & & & Total: $74 \mathrm{n}$ & & & \\
\hline
\end{tabular}

Seguindo a ordem de produção, o primeiro protocolo verbal é o de Dominó, 10 anos de idade, produzido no dia 29/08, das $10 \mathrm{~h} 11$ às $10 \mathrm{~h} 22$, totalizando 11 minutos. O estudante

\footnotetext{
${ }^{15}$ Neste tempo não está inserido o tempo destinado às explicações, demonstração e esclarecimentos de dúvidas dos estudantes.
} 
escolheu o jogo Soccer Physics e o denominado Os Simpsons - The Ball Of Death. Damas, de 11 anos de idade, produziu seu protocolo verbal no dia 07/11, das $9 \mathrm{~h} 12$ às $9 \mathrm{~h} 30$, totalizando 18 minutos. Inicialmente, ela acessou o Click Jogos <www.clickjogos.com.br>. Em seguida, o jogo Stan - Meu Novo Cãozinho; após, o Strawberry Shortcake 2. Também produzido no dia 07/11, das 10h29 às 10h42, o terceiro protocolo verbal, de Xadrez, 11 anos de idade, totalizou 13 minutos. Primeiramente, o estudante acessou o Click Jogos <www.clickjogos.com.br> e elegeu o jogo Ninja Total - Acampamento Ninja. Porém, como o jogo estava demorando para carregar, Xadrez escolheu outro, o Birdy Fruit; depois, optou por Billiards. O quarto protocolo verbal selecionado foi produzido, no dia 21/11, das $9 \mathrm{~h} 21$ às 9h53, por Trilha, de 10 anos de idade, a partir dos jogos Messy Talking Ginger e Papa's CupCakeria.

Utilizamos o formulário, arquivo criado no programa de edição de textos, ao realizar a transcrição, para registrar as informações sobre: o sujeito (nome e idade); o protocolo (data e horário de realização - início e fim); o jogo escolhido (título, endereço de acesso e descrição); as telas; os enunciados proferidos pelos estudantes durante a produção dos protocolos; observações sobre os sujeitos (seus movimentos corporais, expressões faciais e, especialmente, suas ações, por meio do movimento do mouse). Após transcrever os protocolos verbais, fizemos uma cópia do arquivo, conservando o material original, exatamente como os enunciados se encontravam registrados. Assim, procedemos com o tratamento do corpus, ou seja, demos continuidade a AC com à codificação e, em seguida, à categorização.

\section{A codificação e categorização do corpus}

Impregnadas pelo corpus, iniciamos o processo de codificação, ou seja, da transformação dos enunciados verbais registrados no questionário online, pelos 20 estudantes, e dos enunciados verbais, visuais e sonoros registrados nos protocolos, por Dominó, Damas, Xadrez, Trilha, por recorte (seleção das unidades), enumeração (opção das regras de contagem), classificação, agregação (escolha das categorias), permitindo atingir a representação do conteúdo. No processo de codificação, utilizamos o arquivo, criado no programa de edição de textos, armazenando todos os enunciados verbais registrados no questionário online e nos protocolos verbais, explorando as ferramentas "cor do realce do texto"16, "novo comentário" e "localizar". Desse modo, ao realizar mais uma vez a leitura aprofundada e cuidadosa dos enunciados do corpus, as cores disponíveis na ferramenta "cor

\footnotetext{
${ }^{16}$ Ao utilizá-la o texto fica destacado como se tivesse utilizado uma caneta marca-texto.
} 
do realce do texto" foram utilizadas para identificar e codificar, a partir dos objetivos da pesquisa, os enunciados com possíveis unidades de análise. Empregou-se a ferramenta "novo comentário" para inserir considerações sobre o contexto de determinado trecho identificado e categorizado e a ferramenta "localizar" para facilitar a localização de palavras no arquivo. Além de utilizar diferentes cores para codificar os enunciados, nesse ciclo também se substituiu a identidade dos participantes.

Ao fragmentar e desconstruir os enunciados registrados pelos sujeitos no questionário online e nas transcrições dos protocolos verbais, antes organizados na sequência conforme apareciam e separados por autoria e data de criação, questionamos: será possível construir outra ordem a partir da "desordem" de cores dos códigos criados? A resposta a esta pergunta surge com o próximo processo da $\mathrm{AC}$, consistindo na categorização (BARDIN, 1979, 2004). Também fizemos uma cópia do arquivo anterior, da codificação, para registrar o processo desenvolvido. Em um desses arquivos, realizamos leitura aprofundada, agora dos enunciados codificados, identificando e nomeando categorias e agrupando os enunciados semelhantes em tabelas, em razão dos caracteres comuns destes elementos. $\mathrm{O}$ fato de no ciclo de categorização termos utilizado, como código, as diferentes cores facilitou o agrupamento dos enunciados semelhantes. Assim, no processo de categorização, uma nova ordem revela-se a partir da leitura do corpus, unindo os enunciados semelhantes, identificados e codificados, porém, espalhados no arquivo do ciclo de codificação.

A partir da transcrição dos protocolos verbais de Dominó, Damas, Xadrez, Trilha, identificamos e nomeamos quatro categorias: “Qual é a porta de entrada do Click Jogos?”, “Como acontece a escolha do jogo?”, “Jogar é experiência de leitura?” e "Qual é a porta de saída do Click Jogos?”. Em "Qual é a porta de entrada do Click Jogos?”, primeira categoria, reunimos os enunciados dos estudantes demonstrando como eles acessam o Click Jogos, ou seja, o caminho percorrido até o site. Intitulamos “Como acontece a escolha do jogo?", a segunda categoria, avaliando e evidenciando os enunciados de como os estudantes escolhem os jogos no Click Jogos, diante da diversidade de opções disponíveis.

"Jogar é experiência de leitura?", título da terceira categoria, foi composta pelas seções "Por enquanto eu só estou esperando o jogo carregar", "Deixa eu ver como é que eu faço", "Eu acabei de passar de fase" e "Que nem você faz na vida real, é bem legal!". A análise da posição responsiva (BAKHTIN, 2003, 2004) dos estudantes, perante os enunciados do site, revela suas estratégias de leitura e navegação (SOLÉ, 1998, KATO, 1999 e SANTAELLA 2004, 2014a, 2014b, 2014c) e examina se a atividade de leitura e jogo pode revelar a experiência (LARROSA, 2002, 2011). Na categoria "Qual é a porta de saída do 
Click Jogos?", reunimos os enunciados dos estudantes demonstrando como eles saem do Click Jogos.

Seguindo as fases definidas para a AC, a partir da definição das categorias, chegamos, finalmente, à produção da inferência. Esta corresponde a um texto descritivointerpretativo a partir enunciados do corpus, ou seja, a comunicação das novas compreensões atingidas ao longo do processo de organização, codificação e de categorização do corpus (BARDIN, 1979, 2004). Buscamos, ao retornar e analisar os enunciados originais dos estudantes, construir novos enunciados sobre o fenômeno pesquisado, expressando o olhar das pesquisadoras, suas compreensões a partir do corpus da pesquisa.

\section{Considerações finais}

Este artigo objetivou discutir os instrumentos metodológicos explorados no processo de construção de dados, numa pesquisa empírica de caráter qualitativo, para investigar as estratégias de leitura aplicadas por crianças, ao jogar no site Click Jogos. A metodologia foi o resultado do exercício autoral das pesquisadoras que, antes de empregar a AC, no processo de organização, codificação, categorização e inferência do corpus, configuraram um encaminhamento coerente com o objeto de estudo e a fundamentação teórica, articulando-o aos instrumentos e procedimentos metodológicos: criação e a aplicação de questionário online e a produção dos protocolos verbais de áudio e vídeo pelos sujeitos enquanto liam e interagiam com jogos do seu interesse.

Dessa forma, por meio do questionário, foi possível obter informações dos sujeitos sobre suas percepções e seus hábitos de leitura explorando as telas de desktops, notebooks, tablets e smartphones para variados fins, entre eles, jogar. Além disso, esse instrumento facilita o armazenamento, a tabulação e garante a privacidade das informações fornecidas pelos sujeitos aos pesquisadores. O site Click Jogos, o mais citado pelos estudantes, composto por grande quantidade de jogos digitais online apropriado e de interesse dos interlocutores, foi selecionado para a produção dos protocolos verbais "talk aloud" e "think aloud", "falar em voz alta" e "pensar em voz alta". Estes, buscando garantir a fidelidade do processo realizado pelos sujeitos, possibilitaram o registro por meio de áudio e vídeo do que os participantes falavam e estavam fazendo e pensando durante a interação com os jogos, não exigindo a retrospecção para narrar suas ações após serem executadas.

Constatamos que, durante a gravação do percurso e transcrição dos protocolos verbais, quando os estudantes estavam entusiasmados no jogo, aumentavam o tom de voz, reduziam ou interrompiam sua fala. Apesar disso, e dos eventuais problemas ocorridos nos equipamentos que impediram a captura de alguns arquivos de áudio e vídeo, os protocolos 
verbais e também o questionário online foram importantes instrumentos metodológicos para a obtenção dos dados, e posterior organização, codificação e categorização do corpus propostos na Análise de Conteúdo (BARDIN, 1979, 2004). Por fim, a exploração dos questionários online, protocolos verbais e outros instrumentos metodológicos, existentes e novos, são relevantes para dar continuidade aos processos de pesquisa sobre diversos temas, revelando o exercício de autoria dos pesquisadores, sobretudo ao buscar desvendar novas práticas de leitura em coerência com o objeto de estudo e com a fundamentação teórica da pesquisa.

\section{Referências}

BAKHTIN, Mikhail. Estética da criação verbal. 4.ed. São Paulo: Martins Fontes, 2003.

BAKHTIN, Mikhail. Marxismo e filosofia da linguagem: Problemas fundamentais do Método Sociológico na Ciência da Linguagem. 11.ed. São Paulo: Hucitec, 2004.

BARDIN, Laurence. Análise de conteúdo. São Paulo: Edições 70, 1979.

BARDIN, Laurence. Análise de conteúdo. Lisboa: Edições 70, 2004.

BOEIRA, Adriana Ferreira. Ler e jogar ou jogar e ler?: estratégias de leitura empregadas por estudantes do $5^{\circ}$ ano do ensino fundamental ao jogar no Click Jogos. 2016. 233 f. Tese (Doutorado em Letras) - Programa de Doutorado em Letras - Associação Ampla UCS/UniRitter. Universidade de Caxias do Sul, Caxias do Sul. Disponível em: <https://repositorio.ucs.br/handle/11338/1440>. Acesso em: 30 nov. 2020.

ERICSSON, K. A.; SIMON, H. A. (1993). Protocol analysis: verbal reports as data. MIT Press, Cambridge, MA.

KATO, Mary Aizawa. O aprendizado da leitura. 5.ed. São Paulo: M. Fontes, 1999.

LARROSA, Jorge. Pedagogia profana: danças, piruetas e mascaradas /. 4.ed. Belo Horizonte: Autêntica, 2001.

LARROSA, Jorge. Notas sobre a experiência e o saber de experiência. Revista Brasileira de Educação, n 19, p. 20-28, jan/fev/mar/abr 2002. Disponível em: <http://www.scielo.br/pdf/rbedu/n19/n19a02.pdf>. Acesso em: 07 nov. 2020.

LARROSA, Jorge. Experiência e alteridade em educação. Revista Reflexão e Ação, Santa Cruz do Sul, v.19, n2, p.04-27, jul./dez. 2011.

LÉVY, Pierre. O que é virtual? São Paulo: Editora 34, 1996.

SANTAELLA, Lucia. Navegar no ciberespaço: o perfil do leitor imersivo. São Paulo: Paullus, 2004.

SANTAELLA, Lucia. Gêneros discursivos híbridos na era da hipermídia. Bakhtiniana, São Paulo, 9 (2): 206-216, Ago./Dez. 2014a. 
SANTAELLA, Lucia. O leitor ubíquo e suas consequências para a educação. In: TORRES, Patrícia Lupion (Org.). Complexidade: redes e conexões na produção do conhecimento. Curitiba: SENAR - PR., 2014b.

SANTAELlA, Lucia. A condição expandida da leitura. Verbo, São Paulo, n. 9, p. 29-31, ago. 2014c. Disponível em: <http://www.abeu.org.br/ABEUMaster/imagem/RevistaVerbo/Pdf/revistaverbo2014_9.pdf>. Acesso em: 12 out. 2020.

SANTAELlA, Lúcia; FEITOSA, Mirna. Mapa do jogo: a diversidade cultural do games. São Paulo: Cengage Learning, 2009.

SOLÉ, Isabel. Estratégias de leitura. 6.ed. Porto Alegre: Artmed, 1998.

VAN SOMEREN, M. W.; BARNARD, Y. F.; SANDBERG, J. A. C. The think aloud method: a practical guide to modelling cognitive processes. London: Academic Press, 1994.

Artigo recebido em: 08/01/2021. Artigo aceito em: 11/02/2021. 